"Fight against administrative corruption within governmental organizations from motto to practice (case study: Ministry of Economic Affairs and Finance)"

\begin{tabular}{ll} 
AUTHORS & $\begin{array}{l}\text { Samieh Darsareh } \\
\text { Mehrdad Bastanipour }\end{array}$ \\
\hline ARTICLE INFO & $\begin{array}{l}\text { Samieh Darsareh and Mehrdad Bastanipour (2016). Fight against administrative } \\
\text { corruption within governmental organizations from motto to practice (case study: } \\
\text { Ministry of Economic Affairs and Finance). Problems and Perspectives in } \\
\text { Management, } 14(3-s i), 307-316 . \text { doi:10.21511/ppm.14(3-si).2016.02 }\end{array}$ \\
\hline DOI & http://dx.doi.org/10.21511/ppm.14(3-si).2016.02 \\
\hline RELEASED ON & Thursday, 15 September 2016 \\
\hline JOURNAL & "Problems and Perspectives in Management" \\
\hline FOUNDER & LLC "Consulting Publishing Company "Business Perspectives"
\end{tabular}

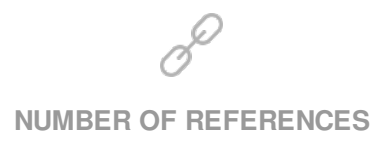

0

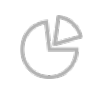

NUMBER OF FIGURES

0

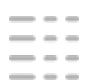

NUMBER OF TABLES

0

(C) The author(s) 2023. This publication is an open access article. 


\title{
Fight against administrative corruption within governmental organizations from motto to practice (case study: Ministry of Economic Affairs and Finance)
}

\begin{abstract}
Administrative corruption in a simple definition is violation of a law for personal benefits by utilization of job position. It is a phenomenon within today's world as one of the most important obstacles on the way of societies' progress. The impact of different factors in forming corruption has given it a complicated nature. Administrative corruption is a correlative issue and it is different according to value system of each society. This article is trying to present a solution in order to fight against administrative corruption through classification of staff with the help of explaining the relation of their perception, sensation and commitment towards corruption and corrupted situations. Present study in terms of purpose is developmental-practical, and in terms of execution and based upon research purposes is a survey. The study population is the staff of Ministry of Economic Affairs and Finance in 2015. In order to explain perception, sensation and the behavior of staff, the questionnaire of administrative corruption is designed in three dimensions: perceptive aspect (cognitive) which includes items for assessing the status of awareness and recognition of staff from instances and consequences of administrative corruption; sensation aspect which includes items for assessing the vision and tendencies of staff towards corruption, and behavioral aspect which is formed from items for assessing the behavior of staff in facing with corruptive situations. In order to identify the reasons of corruption two questionnaires of "National identity" and "Organizational culture" have been designed. The result of the research was that the perpetrators of corruption can be divided into three categories. First category is the staff that their perception is positive, it means that they have adequate cognition from manifestations and corruption consequences and their feeling about corruption is negative, it means that they consider it as an ominous phenomenon, but they are guilty of corruption. Second category is the staff that their perception is positive, they don't see corruption as an ominous phenomenon. Consequently, their feeling toward corruption is positive, and they perpetrate it. The third category is the staff whose perception is negative, their feeling is uncertain, and they perpetrate it. The behavior of these categories will be interpreted in form of related theories. The significant note is that despite the tendency average to practice administrative corruption among governmental staff is lower than assumed average and it indicates that there is a protection of corruption perpetration, but the rank of our country is not favorable the International Organization report. This warning made the researchers to provide new solutions to help resolving this social issue by reviewing current solutions for prevention, and fighting against administrative corruption, regarding the richness of evaluating system in Iran.
\end{abstract}

Keywords: corruption, administrative corruption, corruption perception, sense of corruption, corruption behavior, organizational culture, national identity.

JEL Classification: D73, M12, Z10.

\section{Introduction}

Nations role is undeniable in promotion of the states. If we accept that healthy nation is the breeder of healthy governors and politicians, we shall accept that there will be no any sane society that avoids fighting against corruption. Having healthy and dynamic organizations is essential for growth and comprehensive development of societies. The feature of healthy organizations is not only in having high profit or the number of its employees and managers, sane organization is an organization formed by creative, constructive and committed manpower (Nawaz, F., 2009). Healthy organization will challenge successfully with internal and external obstacles and conduct them effectively in accordance with organizational purposes. One of these deterrent forces is administrative corruption (Fokuoh, E., 2008). Studies undertaken in the field

(c) Samieh Darsareh, Mehrdad Bastanipour, 2016

Samieh Darsareh, University of Tehran Kish International Campus, Kish, Iran.

Mehrdad Bastanipour, University of Tehran Kish International Campus, Kish, Iran. of procedures of doing tasks indicate that corruption at level of organization is the foundation of situations that exist in work procedures (Alatas, V., Cameron, L., 2009). In fact, the more the procedures are not following the laws (even if the law is inappropriate), phenomena like extortion, bribery will happen (Dong, B., 2010). Now the question is why there is violation of the law? Why employee is motivated to violate the law? Why the client is tending to violate the law? Why citizens of some nations are sensitive about such phenomenon, while it is not important in some other countries? In order to answer the above questions, the employees tow government agencies under the Ministry of Economic Affairs and Finance in Iran, including customs, taxation that has been chosen as a case study. The reasons for choosing these organizations were: first, these organizations are having important role in country's economy and each economic situation is potential for administrative corruption, second, the clients of these organizations are doing commercial activities and due to that they are facing two or more countries or, in other words, are facing 
two cultures during their international trades. Therefore, we can collect useful information from the questionnaire relating to this group regarding role of culture and national identity in increasing or decreasing administrative corruption.

Corruption is an issue involving all the organizations incessantly and forming the core idea of many scholars and politicians. Although it is stated that: "totally, corruption is not related to the culture of countries and a country with high level of culture can get involved with corruption" (Lee, W.S., 2013), but the authors of this article believe that nations' culture is having significant role in increasing or decreasing such phenomenon and this is how we can assume a reason for why corruption is correlative within countries.

Administrative corruption is one of the main problems of developing countries, finding solution for it has involved many experts and researchers of general law-makers (Lambsdorff, J.G., 2011). About administrative corruption consequences, it is enough to mention that "corruption is the reason of many disorders and the source of problems like inequality, poverty, resources waste, reduces reliance on law, governments institutions and serious obstacle for development within third world countries" (Chene, M., 2012). Decline in public confidence is the most important consequence of corruption, since, within the system of democracy, public confidence is considered as the asset of government and its survival. Based on a research done by Transparency International, $60 \%$ of interviewees have announced that the main reason of financial corruption within developing countries is the low salary of government employees; therefore, in most of such administrative systems, works are not progressing without bribes (World Bank, 2012).

Although annual reports of Transparency International (2012) regarding corruption perception index indicate that there is no country without administrative corruption, there is a significant difference between the degrees of corruption within different countries. The flow of CPI indicates that this index, during past years in Iran, was not having successful improvement and the corruption control mechanisms have not been taken serious (World Bank, 2011). Based on previous international researches, Iran's administrative system is suffering from corruption. According to the reports by Transparency International Organization, Iran during 2003 to 2009 in terms of administrative corruption has been downgraded, in a way that it went down from 78 to 168 , but during 2010 it has promoted from 168 to 146 (22 levels up) and during 2012 it has moved to rank 120 with 26 levels promotion (Afzali, 2011 , p. 257). It is clear that this index for Iran, which is based on religious system, is not an appropriate index for achieving considerable development by government, and it is, probably, the main obstacle against economic growth and development.

\section{Definition of concepts}

Administrative corruption: it refers to a behavior that the individual does in order to meet his personal benefits and achieve more welfare or better position, outside the official framework of duties as a governmental role (Scott, J., 2003).

Organizational culture: Danison defines organizational culture as powerful force that determines the way of performance and missions, organizational culture indicates sum of values, beliefs, norms and agreements that the organization is having mutual aspects with its employees (Daft, 2001, p. 33).

National identity: national identity is the sense of belonging and commitment for national society and for whole society and we can say that national identity means that, the individuals of a society feel a common origin (Yousefi, 2001). National identity includes different constructive elements like national, religious, cultural, social, human values and it is manifested in aspects of cultural, social, historical, geographical, political, and lingual, etc.

1.1. Theoretical background of the research. On the one hand, corruption originates from both complicated and traumatic bureaucracy, and incorrect social norms and values vary dependent on law-makers' perspectives, as well as social interaction styles in different societies. The main core of organizational culture is formed by values shared by members of the organization; based on which the organization's internal behavior is formed (Gholizadeh, A., Ebrahimzadeh, R., 2010). Culture is a set of key values broadly accepted by the members of the organization (Yilmaz, C., 2008). In fact, organizational culture complements organizational performance. Richness of this culture provides a sense of empathy among all the members of the organization helping them to see themselves in a line. Organizational culture has the ability to prevent currents accompanied by administrative corruption. This factor can control the behavior of employees by introducing appropriate behavioral models leading their behavior through establishing appropriate motivational methods. In addition, socially speaking, organizational culture is considered a cohesive tie that can attach elements of the organization through providing appropriate standards (in connection with what members must do or say) (Jafari Kashtiban, 2012). The significance of organizational culture in forming employees' behavior and inducing internal commitment is such that 
"Stanley Davis" in his book, Organizational Culture Management, calls it an unofficial organization that can create a sense of commitment and responsibility within individuals towards something which is beyond personal benefit (Rabiei and Asef, 2012). Accordingly, the present article is to explain the relationship between the variable organizational culture and employees' tendency to administrative corruption.

Questioning "identity" is a question of values and norms of individuals within different groups. Having different identities and comparing identical forms to identify themselves, individuals have been always seeking to make differentiation between themselves and others; a differentiation which is always considered a sign of specific values and norms for (an) individual/s. In fact, the differentiation has been present not only among (an) individual/s', but also among their values and norms (Zahiri, 2005, pp. 105106). A dimension of this issue is the analysis of social identity in modern era, since most of identity-making resources and models like religiosity are weakened, while consumption behaviors have become the basis for establishing social identity. In other words, individuals seek their quiddity and self in the context of a consuming and materialistic culture (Zokaei, 2007, p. 101). Therefore, such a consuming and materialistic culture becomes a motivation for acquiring more property (even illegitimate).

One of the indicators of identity is "religious beliefs" being considered one of the corruption deterrent factors. According to Dorkim, religion, among other things, is a system, passing through which individuals represent the society they belong to, as well as their covered, but deep interrelationships. Dorkim strongly supports the fact that religions are not only an issue of believing, but all religions are assuring disciplined formalities and rituals in which, as collective formal ceremonies, the sense of establishing a group is confirmed and reinforced. He believes that, within traditional cultures, almost all aspects of life are influenced by religion (Kribe, 2009, p. 133). Gidnes believes that modernity have changed the identity-making process within the modern world by changing the conditions and identity-making traditional frameworks and weakening or destructing traditional identity resources.

Although there is not any consensus on identity resources among socialists, it is agreed upon that through developing the process of modernity, traditional identity resources will gradually diminish to the extent that they will lose their hegemonic power. During modernity and the development of globalization, traditional resources of identity including religion are going to vanish in all the societies proportionately (Gidnes, 2007, p. 178). Religion creates values and forms norms, gives sanctity to fixed ethical values, gives meaning to human life and effectively guides human for perfection in the world and hereafter. It has different functions for the society and individual. Religion creates and establishes a sense of consensus and community for the society, prohibits anti-social behaviors including administrative corruption and suggests ways for re-solidarity of offenders (Tanhaei, 2011, p. 5). Based on these concepts, the relationship of the variable national identity and the tendency to commit administrative corruption could be explained by a focus on two indicators including ethical identity and religious identity.

1.2. Empirical background of the research. Rabiei and Bigdeli (2010) carried out a research study entitled "cultural pathology for promoting administrative health of governmental and nongovernmental organizations". The findings indicated that in both governmental and private organizations organizational culture is effective in promoting the health of administrative systems, and organizational stories and models were the strongest indicator, while traditional values were the weakest cultural indicator in reducing administrative corruption. Finally, they recommended cultural solutions like emphasis on traditional and ethical values, cooperative management and so forth.

Abbasi and Jamalpoor (2011) conducted a study entitled "The role of organizational culture in promoting the health of administrative systems and the level of people's satisfaction". Their principal approach was to stress the establishment and implementation of a preventive system against corruption with roots in society's culture and cultural development instead of relying on traditional procedures and punishment after committing corruption. The approach has reviewed measures like giving identity to employees, fixing social system, establishing internal commitment for employees, fixing motivational methods, presenting appropriate behavioral models and functions of organizational culture in order to establish an atmosphere that can both proscribe administrative corruption and internalize organizational culture to maintain the dignity of people within the administrative system.

Sheikhi (2011) carried out a research entitled "Factors affecting administrative system health and growth of ethical values". The research was to explain effective factors of the health of administrative systems and growth of ethical values by utilization of Quran verses, and theoretical and practical methods of Imams. He, by analysis of Islamic references' content and Shiite Imams' theoretical and practical sayings and practice, 
concluded that administrative systems health and ethical values' growth, are, on the one hand, under the impact of ontological and anthropological foundations dominating the beliefs of employees and, on the other hand, under the influence of three values, exo- and intra-organizational factors.

Hasani and Shams (2012), conducted a study entitled "solutions for fighting against administrative corruption based on Islamic values". The main question of the study was "solutions for fighting against administrative corruption based on Islamic values". In order to answer it, the approach of Islamic values was considered as the theoretical framework with an emphasis on the theory of limitations based on managing administrative corruptions gorges. In this research, the inferential method was utilized by considering precautionary principle within religious researches. Accordingly, exclusivism, lack of accountability, lack of meritocracy in selections, lack of social responsibilities among citizens, and lack of transparency in administrative systems, were recognized as administrative corruption factors.

Hasandoost Farakhani and Yazdan Panah (2014) conducted a research study entitled "Review of students' tendency to administrative corruption and its determinants: the case of Shahid Bahonar University of Kerman)". The results indicated that variables social belonging, social cohesion, adherence to religious values, social commitment, lack of proportionality between ends and means, dignity failure and, ultimately, self-concept have the strongest relationship with administrative corruption. Results of MANOVA indicated that among the independent variables, the variables lack of proportionality between ends and means, social belonging, social commitment, dignity failure and social cohesion have the highest predictive power toward the dependent variable.

Taleghani et al. (2014) have a research entitled "a review of individual and organizational factors affecting administrative corruption in branches of Bank Sepah in Qom". Results indicated that there are significant relationsips between religious commitment, personality characteristics, communication style, leadership style and the quality of working life as "individual factors" and administrative corruption. On the other hand, there was a significant relationship among the systems of control and monitoring, salary and wage system and work processes as "organizational factors" and administrative corruption.

Moore (2008) examined the role of lack of ethical commitment as an important principle in unethical decision-making in organizations to better recognize organizational corruption. Results indicated that lack of commitment to ethical principles has a positive impact on beginning, facilitating and developing administrative corruption (as cited in Kuhlmann, T.M., 2008).

Salim and Bonits (2009) examined the relationship between culture and corruption through a cross-national study carried out based on Hafsted cultural model and claimed that collectivism and uncertainty increase the level of corruption (Seleim, A., Bontis, N., 2009).

\section{Questions and research hypotheses}

From different definitions of administrative corruption, we can find out that governmental agent violates the rights for service-holder or government by using job position for personal interests, while most of governments are having evaluation system, but reviews indicate that this phenomenon is existing in all countries relatively, and the important note is that although natural reaction is to protest by the service-holder, it is observed that sometimes service-holder is not protesting and also cooperates with the governmental employee in a corruption. This is why, in addition to review the status of organizational culture, national identity and cognitive dimensions, and emotional and behavioral traits of employees shall consider the purpose and nature of rules and regulations more.

The main questions of this research are:

1. The status of employees in facing with administrative corruption.

2. Regarding the relation among perception, feeling and behavior of employees in facing with corruption, how can we analyze their behavioral contradictions and their belief backgrounds?

3. Regarding the richness of evaluation system, how can we use it for making it more effective against corruption?

4. What new solutions can we introduce for prevention and fight against corruption?

By help of designed questionnaires, we can explain the answer first and second questions but, in order to answer questions 3 and 4 , in addition to questionnaire, it is required to review scientific theories and conducted researches about prevention and fight against corruption and also the experiences of countries and below hypotheses will be popped out of them:

1. Readiness or tendency to practice administrative corruptions among employees lower than middle level.

2. Awareness level increase of personnel can be effective on resolving contradiction among perception, feeling and behavior of employee in 
facing with a corruptive situation from cognitive dissonance and perception management.

3. Attention to national identity beside organizational culture is effective for prevention and fight against corruption.

4. Preventive solutions and fight against corruption shall be adjusted in accordance with cognitive, feeling and behavioral aspects of governmental employees.

\section{Research methodology}

In terms of purpose, the present research follows a developmental-applied approach. In addition, in terms the implementation method and based on research goals, the survey method was selected for collecting the intended data. The population included the employees of subsidiary organizations of the Ministry of Economic Affairs and Finance. A sample size of 200 was determined. Simple random sampling method was applied. A questionnaire was used to collect the data. In order to test the status of employees in facing with administrative corruption (readiness or tendency to commit administrative corruption among employees), 22 items were developed. The questionnaire had three subscales: the cognitive subscale, including 6 items in the form of a 5-point Likert-type scale (never, very low, a few, high, very high), the emotional subscale including 6 items in form of 5-point Likert-type scale (completely agree to completely disagree), and the behavioral subscale including 10 items (never, very low, a few, high, very high). The questionnaire of organizational culture was designed based on the organizational culture model by Denison et al. (2000) including four dimensions: involving in work (10 items), similarity (10 items), compatibility (10 items) and mission (10 items) in form of 5-point Likert-type scale (completely agree to completely disagree).

In order to test national identity, Lotf Abadi and Nowruzi's (2006) national identity questionnaire was used. The questionnaire includes three dimensions: belonging to country ( 3 items), national and cultural art and experience value ( 7 items) and commitment and empathy to motherland (4 items). The items of the questionnaires were delivered to some of experts in order to be validated. As a result, the face and content validity were checked. Cronbach's Alpha coefficient for each variable was more than 0.7 and, as a result, the reliability of the questionnaire was confirmed as well. In order to determine the research hypotheses, inferential statistics at the 0.05 significance level (one-sample t-test, Pearson's correlation coefficient and multivariate regression) were conducted with SPSS v. 19.

\section{Results}

The probability value of one-sample t-test to test the first hypothesis stating the presence of a significant statistical difference between the hypothesized and actual means of the variable is more than 0.05 . On the other hand, the values of lower and upper limits indicate that these values are in the same direction for all the variables. The positive sign in from of lower and upper limits indicates that the mean value of respondents' responses to these indicators is larger than 3. In general, the results of analysis of mean values indicate that the t-test value is lower than the critical value (1.96). Therefore, the value of readiness to commit administrative corruption among employees is lower than hypothesized mean (3). This confirms the first hypothesis in that most employees (facing with corruption situation) do not tend to commit administrative corruption. In a similar method, testing the second hypothesis for the existence of behavioral contradiction with attitudes and feelings of employees in facing with corruption, the examination among the including people who were punished due to manifestations of different administrative corruption indicated that despite lack of tendency to practice corruption:

- Their knowledge and recognition of instances and consequences of administrative corruption is low and it indicates that the instances of corruption is much extensive than what the employee considers it corruption. Therefore, perceptional dimension of employees towards corruption is poor.

- Feelings and tendencies of employees toward corruption (regarding benefits and risks ahead) is negative and considered the administrative corruption as an ominous phenomenon.

To confirm the third hypothesis based on the significance of national identity role alongside the organizational culture in prevention, fight against administrative corruption and promoting evaluation system, studies indicated:

- According to Table 1, obtained significant amount of $\mathrm{F}$ in error level lower than 0.05 , indicates the regression equation is significant. Amount of correlation coefficient indicates that there is a very strong and inverse relationship between national identity and organizational culture with mount of tendency to corruption. Adjusted coefficient of determination $\left(\mathrm{R}^{2 . \mathrm{adj}}\right)$ indicates that national identity and organizational culture are explaining the changes of tendency to administrative corruption $78.7 \%$ and $50.4 \%$, respectively. Regression coefficient determines the contribution of independent variable to predict the dependent variable changes, in other words, for each unit 
increasing in national identity of employees, $76 \%$, and per each unit increasing in organizational culture of employees, 50 percentage of their tendency will be decrease for administrative corruption. T-statistic and error level less than 0.01 of it indicate that variables of interest had statistically significant effect on explaining changes of tendency to administrative corruption.

Table 1. Results of regression correlation coefficient between national identity/organizational culture and tendency to administrative corruption

\begin{tabular}{|l|c|c|c|c|c|c|}
\hline The independent variable & $\mathrm{R}$ & $\mathrm{R}^{2 . \mathrm{adj}}$ & $\mathrm{B}$ & $\mathrm{T}$ & $\mathrm{F}$ & $\mathrm{Sig}$ \\
\hline Amount of national identity & -0.877 & 0.787 & -0.76 & 38.3664 & 12.472 & 0.000 \\
\hline The independent variable & $\mathrm{R}$ & $\mathrm{R}^{2.2 \mathrm{adj}}$ & $\mathrm{B}$ & $\mathrm{T}$ & $\mathrm{F}$ & $\mathrm{Sig}$ \\
\hline Amount of corporate culture & -0.711 & 0.504 & -0.5 & 20.171 & 406.860 & 0.005 \\
\hline
\end{tabular}

Regarding the fourth hypothesis, based on preventing strategy and fight against corruption, it shall be set appropriate with cognitive, emotional and behavioral dimensions of government employees; first, we shall review the background of solutions against corruption and, then, action towards solutions will be done in future discussions.

4.1. Background of approaches to combat administrative corruption. Here, according to prior studies, some other pointed strategies are mentioned to combat administrative corruption:

- Rabiei and Bigdeli (2010) suggested cultural strategies like: emphasis on traditional and moral values, cooperative management and things alike for health promotion administrative of governmental and nongovernmental organizations.

- Fundamental approach that Abbasi and Jamalpour (2011) have insisted on was to establish a preventive system against corruption instead of relying on procedures based on punishment after committing administrative corruption, that its central core is culture of society and making culture as a necessary issue. This approach provides actions like giving identity for employees, stabilizing social system, creating internal commitment in employees, stabilizing motivational methods and providing appropriate behavioral patterns, what Islam wants from a Muslim - to care about his own actions and behaviors and not to fail.

- Sheikhi (2011) also explained three types of intellectual, ideological amendments, and internal and external of organization essential to administrative system health.

- Hasani and Shams (2012) have also proposed solution to fight against administrative corruption, strategies include: strengthening internal monitoring (piety) and social control (enjoining good and forbidding wrong); increasing health of administrative system agents; institution-building, transparency, transparency-oriented, attention to livelihoods of employees, promoting the culture of punctuality, and restoring sense of social responsibility.

- Salim and Bontis (2009) have declared that policy-makers must establish official systems for determining procedures like dynamic systems and flexible promotion. They must reinforce collaborative culture as well.

4.2. Proposed strategy to combat administrative corruption. Until now, the approaches of most researches to fight against corruption were relying on laws, arbitration, management or organization.

Regardless that, for each group of individuals who are tending to commit corruption, we shall consider a different solution. In other words, institutional approach against corruption is an issue focused for years and there are many such institutions in most countries, including Iran, to stop this phenomenon, while administrative corruption is growing. It is clear that this research is not relating to those who are not practicing administrative corruption since it is obvious that those who are influenced by the rich organizational culture and strong national identity are positive in terms of cognitive and behavioral aspects, they are people for whom, in addition to attachment to their homeland, citizen, and future generation, due to strengthening ethics and beliefs, adequate deterrence for avoiding administrative corruption is internalized that encouraging them can impact others to stop getting involved with administrative corruption. It is surprising, although there is a reversal relation between national identity and organizational culture with feeling and behavioral aspects of administrative corruption, and despite old history of civilization and culture of Iran, and despite the spirit of laws and regulations is rooted from religious studies, and despite government employees are coming from the nation who are tending healthy administration, the first hypothesis of this research is that tendency to practice administrative corruption among employees is above the average. But, since the purpose of this research is to explain the features of perpetrators of corruption and introduce solution to stop it, individuals have been categorized in three groups and, according to the 
perception, sensation and behavioral readiness of the members, solutions have been suggested to them about corruption. People who perceive corruption positively, their feeling about corruption is negative, but they practice it:

1. People who have a positive perception of corruption, negative feelings towards corruption, but they do that.

Reason: it seems, disrespect of this group to laws and regulations is that, according to their viewpoint, law is a system that is not caring employees; therefore, employee is not having the feeling of belonging and his cognitive dissonance (conflict between cognition and his behavior) is because of the sense of alienation. National identity of these people is assessed weak.

Solution: for this group of people, the best solution is suggested to help to modify their behavior for more compatibility with their beliefs and attitudes. In fact, it is the same thing that Fistinger has stated about dealing with differences. The people whose perception to corruption is positive, have positive feeling about corruption (they don't consider it as an ominous phenomenon) and they practice it.

Reason: Selfishness is a factor which has made the members of this group to opportunist people, people who despite adequate awareness and recognition and its consequences, don't feel bad about weakening government rights or service-holder to achieve personal interest by using job position. These people are misusing their authorities, they are people who even pretend they are religious to promote their job position and they appear to be good people and this is a method for hiding corruptions they practice. These people are in lack of national identity.

Solution: Developing a mechanism to identify these people and deceasing range of policy-making overlap, and implementation along with strict deal, and keeping them away from positions of authority can be a deterrent in addition to the help of drying up this kind of corruption's root and, also, it can act as preventing in another talented people. People with negative perception toward corruption have indifferent feeling regarding corruption and are guilty of corruption.

2. People with negative perception of corruption, have uncertain feeling regarding the corruption is (indifferent) and are guilty of corruption.

Reason: the root of behavior of these employees is their ignorance and lack of knowledge or their intellectual deviations that are due to gap within education system, appointment and supervision, despite they practice petty corruption, their number in population is considerable. These people, due to insecurity, are experiencing identity crisis.

Solution: education, education, education.

Since, in accordance with viewpoint of many experts of organizational behavior management, the behavior of people is formed under the influence of beliefs and their values. In order to modify behavior and to cure administrative system at first step, we shall reinforce attitudes, national and religious beliefs, including love for homeland, countryman, godliness, hereafter, responsibility, honesty, and trustworthiness. In other words, one of the most important duties of managers is shaping and conducting principal values and organizational culture. In fact, the crucial role of organization leaders is to manage values within organization. It is remarkable that some of these values are the same reinforcement of national identity, since we can state that by strengthening national identity and developing the sense of responsibility to nation and homeland, organizational culture will be richer among employees. Some of scientists are assessing the performance of top management according to achievement and dominance of values and sublime goals within organization. Also, most of researchers have concluded that even if the organizational goals are only profitability, we cannot achieve this goal without attention to organizational culture values. As a result, managers must consider and invest on organizational culture management (Barbaroux, P.E., 2011).

\subsection{Pattern of "Nation's monitoring on state".} The model that considers that one of the ways to control corruption is the supervision and control by people of public services (as main client), the people who have the right to receive services clearly and healthy, the people who consider corruption as an ominous phenomenon and in contrary with national identity and culture, and the people who were the object or subject and now, due to lack of their satisfaction from current status, are changed to active agents. Regarding, administrative corruption is defined as the repetition of administrative violation, therefore, using government to resist corruption (by supervision or prevention or fight against) is a way, which is done by different countries many times, it seems government supervision on government is not having result. In some countries (including Iran) there are many supervisory organizations, for instance, within Iran, each one of three organizations of legislative, executive and judicial are having agents that their main mission is to prevent, control and fight against corruption including administrative one; however, the rank of developing countries, in terms of international transparency organization, is not acceptable. It seems 
that there is a gap within supervisory systems, that is the role of individual, people and society and this issue is referring to accountability, transparency and responsibility, that, in addition to self-monitoring and self-control, are necessary that people shall be aware of their rights and there shall be a procedure to achieve it. On the other hand, considering this note is significant if people didn't report ordinary violations due to being fashionable and routine during a period of time, it indicates that this issue, violation of law is acceptable by people and it can be neglected and the reason is that the law is not fulfilling their benefits, and also violation of law can fulfill their benefits. In other words, if people and society think that system and law are not fulfilling their benefits they will help government agent to practice administrative corruption and they participate in corruption to receive services (considering that the service is their certain right). In order to have the people to control, some issues are significant, namely, social maturity (under the shadow of knowledge and awareness), transparency, security, regulations' revision, in order to fulfill public benefits.

\section{Conclusions}

The results of this research indicated that, on the one hand, the desire of administrative corruption among the staff of statistical population is high. On the other hand, there is a significant relationship between cognitive and emotional dimensions of the staffs affected by individual, organizational status and type of society that surrounds them and behavioral aspect of corruption.

It means the employees with the high scores in variables of "national identity" and "organizational culture" are having low tendency to practice administrative corruption. Therefore, we can state that weakness of organizational culture and undermining national identity among employees can be administrative corruption's factor of expansion. But since, in practice, some of countries with rich culture are also having the issue of administrative corruption, and, on the other hand, the introduced solutions by other researchers for prevention, resistance and fight against corruption couldn't decrease administrative corruption, therefore, it seems that tendency and practicing corruption is almost having root within individual itself (personal identity) and cultural matters (mutual beliefs of society). Regarding the result of present study, there are some suggestions as follows.

Ambiguity in values causes identity confusion of people and societies. Individuals and societies that are not committed to their own national and religious values, will doubt regarding belonging to their identity. National identity and national soul have facade like individual soul. It passes some levels of progress and perfection that the national progress is aligned with the progress of society. In case the national spirit has high existence capacity, there will be civilization through attempt for improvement, its manifestations will be witnessed within social behaviors at level of nation, and beyond the nation; means it passes the local and periodic originality, and reaches to global originality. Reverse of this issue can also happen, in other words, if one of the forming elements of national identity face problem we shall look for "burnt identity". In a society where corruption is normal, certainly one of the elements forming national identity is destructed that its revival requires national determination.

In order to cope with the sense of alienation that sometimes employees will get involved with and considered as one of the reasons is negligence to national or government benefits that causes motivation of committing administrative corruption, managers must provide absorption for cooperation through involving those employees in decisionmaking through opinions, suggestions. It is necessary to organization's managers to give bonus to employees who increase teamwork and give the chance to employees to show their existence through providing their ideas and suggestions. Giving ideas is possible when individuals can indicate their individual capabilities, in this case that individual can internalize their job and to act it as a principal aspect of their own concept. Organization managers must provide an open and constructive atmosphere for employees by making them participate in decision-makings, resolving conflicts, establishing system of suggestions, helping to fulfill spiritual and physical needs, holding training courses, meritocracy, a spirit of creativity and innovation, and use of consultants and experts.

It is necessary that organization managers have a special concentration on founding activities based on understanding and illustrating the fundamental values such as goal and organization strategies. For this purpose, fundamental values and skills must be developed to draw the attention of managers as a part of organization competitive strategies.

Organization managers must motivate and encourage employees who are in direct contact with clients to respect customer needs and follow up their requests and eagerly solve their problems since the existence of professional and experienced staff cause's improvement of service quality and increases the level of satisfaction. Clients expect that the employees will pay attention to ethical and social issues in their behavior and performance, and provide justice at the center of their work. The remarkable note is that the consequence of such behavior earns respect. 
It is clear that, according to the theory of limitation, each system has limitations that make difficulty to achieve optimal efficiency. Laws and regulations are considered as such limitation; despite they are tools for achieving organizations' goals and, finally, optimal serving to the people. But, in some cases, same laws and regulations are considered as system limitations and take organizations far from their main mission (fulfilling public benefits) so people, in order to pass obstacles, accept violation of laws and they don't consider it as an ominous phenomenon, therefore, here rooting is needed instead of focus on the phenomenon. It means, instead of looking for supervisory model, we must revise laws and regulations.

\section{Musts of dealing with administrative corruption}

Create the culture to confront corruption as an ominous phenomenon for the present and future (wanting).
Expand the knowledge to know that corruption is indecent, even if it meets our personal interests (knowing).

Improve the technology to simply identify instances of corruption (being able).

Reform the structure to prevent the entering of unhealthy (corrupted) people to the government as the main trustee of public service delivery (becoming).

Dare to stop violators and corrupted people and establish severe punishment for them.

\section{Recommendations for future researches}

1. Classification of administrative corruption from organized and non-organized perspective and how to deal with each and the way to cope with them.

2. Explanation of relation between perceptions, sensation of government employee's behavior toward structuralized administrative corruptions.

\section{References}

1. Abbasi, Mahdi, Jamalpour, Michaeil. (2011). Role of organizational culture in promoting health of Administrative system and the level of public satisfaction, Cultural Engineering Magazine, 55 (56), p. 44.

2. Afzali, Abdalrahmaan. (2011). Administrative corruption and its impact on development, causes and consequences and strategies exit, Journal of International Law Center President, 28 (45), pp. 257-254.

3. Alatas, V. Cameron, L. (2009). Gender, Culture, and Corrupition: Insight from an Experimental Analysis, Southern Economic Journal, 75 (3), pp. 663-680.

4. Barbaroux, P.E. (2011). A design oriented approach to Organizational change. Insights from a military case study, Journal of Organizational Change Management, 24 (5), pp. 626-639.

5. Chene, M. (2012). Overview of corruption and anti-corruption in Turkey, Transparency International, AntiCorruption Resource Centre.

6. Daft, Richard, All. (2001). Organization design theory. Translated by Mohammad Arabi and Ali Parsaeian, Tehran: Cultural Research Bureau.

7. Denison, D., Cho, H.J. and Young, J. (2000). Diagnosing Organizational Culture: a model and method. Working paper, International for management development.

8. Dong, B., Dulleck, U., Torgler, B. (2012). Conditional corruption, Journal of Economic Psychology, 33, pp. 609-627.

9. Fokuoh, E.A. (2008). The Fight Against Corruption And Its Implications For Development In Developing And Transition Economies, Journal of Money Loundering Control, 11 (1), pp. 76-87.

10. Gholizadeh, A., Ebrahimzadeh, R. (2010). An analytical model of theorganizational culture evaluation in Iransteel industry: a survey research of TukaSteel Investment Holding Company, International Journal of ISSI, 7 (1), pp. 1-10.

11. Giddens, Anthony. (2007). Sociology. Translated by Manouchehr Sabouri. Tehran: Ney publication.

12. Hasandoost Farakhani, Hadi, Yazdanpanah, Leili. (2014). Students Attitudes to administrative corruption and social factors affecting it (the study of students of martyr Bahonar University), Journal of Social Issues Iran, 1, pp. 54-33.

13. Hasani, Ali, Shams, Abdolhamid. (2012). Anti-corruption strategies based on Islamic values, Islam and Research Management, 1, pp. 104-181.

14. Jafari Keshtiban, Masoumeh. (2012). Pathology of administrative system from the causes of administrative corruption and providing approach to combat it (case study of West Azerbaijan Trade Organization). Public administration master's thesis, Islamic Azad University, Science and Research Branch, Urmia, West Azerbaijan.

15. Krayb, Yan. (2009). Classic Social Theory. An Introduction to Marx, Weber, Durkheim, Simmel thought. Translated by Shahnaz mosamaparast, fourth print. Tehran: Agah publication.

16. Kuhlmann, T. M. (2008). Understanding Corruption in Organizations - Development and Empirical Assessment of an Action Model, Journal of Business Ethics, 82, pp. 477-495.

17. Lambsdorff, J.G. (2011). Gender and Corruption: Lessons from Laboratory Corruption Experiments.

18. Lee, W.S. (2013). Engaging in corruption: The influence of cultural values and contagion effects at the micro level, Journal of Economic Psychology, 39, pp. 287-300.

19. Nawaz, F., Musembi, C.N. \& Naomi, H. (2009). Primer on Gender and Corruption, Forthcoming, UNIFEM/UNDP. Available at: www.U4.no.

20. Rabiei, Ali, Asef, Hajer. (2012). Role of culture in the prevention of administrative corruption, Journal of Public Administration, 10, pp. 45-58. 
21. Rabiei, Ali, Bigdeli, Minoo. (2010). Cultural Pathology in health improvement of governmental and nongovernmental organizations, Journal of Religion and Communications, 18 (39), pp. 187-205.

22. Schermerhorn, J., Hunt, J. and Osborn, R. (2005). Organizational Behavior. New York: John Wiley \& Sons Inc., Ninth Edition.

23. Scott, J. (2003). Comparative Political Corruption. New Jersey: Prentice Hall Inc.

24. Seleim, A., Bontis, N. (2009). The Relationship between Culture and Corruption:a Cross-National Study, Journal of Intellectual Capital, $10 \quad(1), \quad$ pp. $165-184 . \quad$ Available at: http://www.business.mcmaster.ca/mktg/nbontis/ic/publications/SeleimBontisJIC10-1.pdf

25. Sheikhi, Mohammadhosein. (2011). Effective factors on health of administrative system and growth of the moral values, Slam and management research, 1 (2), pp. 99-126.

26. Taleghani, Gholamreza, Tabatabaei, Zahra, Ghaffari, Ali. (2014). Review of individual and organizational factors influencing the corruption in Bank Sepah of Qom, Management of organizational culture, 12 (2), pp. 235-253.

27. Tanhaei, Hosein Abolhasan. (2011). Sociology of Religion in the Ancient East. The second edition, Tehran, Bahman Borna.

28. Transparency International. (2012). Available at: http://www.transparency.org/cpi2012/results. Accessed: 10 June 2011.

29. World Bank. (2011). World-Wide governance indicators. Available at: http://info.worldbank.org/governance/wgi/sc_country.asp . Accessed: 15 June 2011.

30. World Bank. (2012). Worldwide Governance indicators: Country Data Report for Iran. Available at: www.worldbank.org/wbi/governance/.

31. Yaghoobi, Mina, Gholami, Farzad, Akbarnezhad, Mahdi. (2014). Review of administrative corruption in the Quran and Hadith, Journal of Islamic Management, 22 (1), pp. 167-195.

32. Yilmaz, C. and Ergan, E. (2008). Organizational culture and firm effectiveness. An examination of relative effects of culture traits and the balanced culture hypothesis in an emerging economy, Journal of World Business, 42, pp. 290-306.

33. Yousefi, Ali. (2001) Inter-ethnic relations and its impact on people's national identity, National Studies, 8 (2).

34. Zahiri, Alireza. (2005). The nature of national identity, Political Science Quarterly, 8 (29), pp. 29-50.

35. Zakkaei, Mohammadsaeed. (2007). Sociology of youth. Tehran: Aagah publication. 